\title{
Assessing unmet anaesthesia need in Sierra Leone: a secondary analysis of a cluster-randomized, cross-sectional, countrywide survey.
}

Mark J. Harris ${ }^{1}$, Thaim B. Kamara ${ }^{2}$, Eva Hanciles ${ }^{3}$, Cynthia Newberry ${ }^{1}$, Scott R. Junkins ${ }^{1}$, Nathan L. Pace ${ }^{1}$

1. Department of Anesthesiology (Rm 3C444), University of Utah Medical Center Salt Lake City, USA

2. Department of Surgery, Connaught Hospital Freetown, Sierra Leone

3. Department of Anæsthesiology Connaught Hospital Freetown, Sierra Leone

\begin{abstract}
Objectives: To determine the unmet anaesthesia need in a low resource region.

Introduction: Surgery and anæsthesia services in low- and middle-income countries (LMICs) are under-equipped, under-staffed, and unable to meet current surgical need. There is little objective measure as to the true extent and nature of unmet need. Without such an understanding it is impossible to formulate solutions. Therefore, we re-examined Surgeons OverSeas (SOSAS) unmet surgical need data to extrapolate unmet anaesthesia need.

Methods: For the untreated surgical conditions identified by SOSAS, we assigned anaesthetic technique required to carry out the procedure. The chosen anaesthetic was based on common practice in the region. Procedures were categorized into minimal anaesthesia, spinal anæsthesia, regional anaesthesia, ketamine/monitored anaesthesia care (MAC), and general endotracheal anæsthesia (GETA).

Discussions: Ninety-two per cent (687 of 745) of untreated surgical conditions in Sierra Leone would require some form of anaesthesia. Seventeen per cent (125 of 745) would require MAC, 22\% (167 of 745) would require spinal anaesthesia, and $53 \%$ (395 of 745) would require GETA.

Conclusion: Analyses such as this can provide guidance as to the rational and efficient production and distribution of personnel, drugs and equipment.

Keywords: unmet anaesthesia, cluster-randomized, cross-sectional, countrywide survey.

DOI: http://dx.doi.org/10.4314/ahs.v15i3.43

Cite as: Harris MJ, Kamara TB, Hanciles E, Newberry C, Junkins SR, Pace NL. Assessing unmet anaesthesia need in Sierra Leone: a secondary analysis of a cluster-randomized, cross-sectional, countrywide survey. Afri Health Sci. 2015;15(3):1028-33. doi: http://dx.doi. org/10.4314/abs.v15i3.43
\end{abstract}

\section{Introduction:}

The World Bank classifies countries into low-, middleand high-income based on the gross national income per capita in U.S. dollars. The divisions are: low-income, $\$ 1,035$ or less; middle-income, $\$ 1,036-\$ 12,615$; and high-income, $\$ 12,616$ or more. ${ }^{1}$

It is recognized that surgery and anaesthesia services in low- and middle-income countries (LMICs) are un-

\author{
Corresponding author: \\ Mark J. Harris \\ Department of Anesthesiology (Rm 3C444) \\ University of Utah Medical Center \\ 30 North 1900 East \\ Salt Lake City, UT 84132-2501 \\ USA \\ Tel: (801) 5816393 \\ Fax: (801) 5814367 \\ Email: Mark.Harris@hsc.utah.edu
}

der-equipped and under-staffed.-21 Most of this data comes from assessments of personnel, supplies and workload at institutions throughout the low resource world. It clearly demonstrates that surgical and anæsthesia services are unable to meet the current need, but gives no sense as to the true extent and nature of unmet need. Without such an understanding it is almost impossible to formulate strategies to resolve the shortfall. To address the knowledge deficit regarding surgical need, Surgeons OverSeas ${ }^{22}$ developed and tested a survey tool, the Surgeons OverSeas Assessment of Surgical Need (SOSAS). ${ }^{23}$ In 2012 this tool was used to assess the prevalence of surgically treatable conditions in Sierra Leone, and revealed that one quarter of the population had a surgical condition needing attention. ${ }^{24}$ In an attempt to determine the corresponding unmet anaesthesia need, we re-examined this data to infer the types and numbers of anaesthetics that would be required to satisfy this unmet surgical need.

\section{Methods}

The original SOSAS survey of Sierra Leone targeted 1875 households randomly selected from study clus- 
ters based on enumeration areas in Sierra Leone. Two randomly selected household members underwenthead-to-toe verbal examinations to identify existing untreated surgical conditions. Conditions were defined with multiple modifiers: anatomic location, aetiology (injury, congenital, mass, etc.), severity of consequent disability, and reason for not receiving care. ${ }^{24}$

After obtaining University of Utah Institutional Review Board approval to assess this dataset (IRB \# 00062903) we assigned types of anaesthetic techniques required to carry out the procedure for the untreated surgical conditions identified in the SOSAS dataset. The chosen anæsthetic technique was based on common practice in the region. If there was ambiguity about the necessary intensity of anæsthetic care, the less complex anæsthetic (fewer resources) was chosen. Procedures were categorized into minimal anæsthesia, spinal anæsthesia, regional anaesthesia, ketamine/monitored anæsthesiacare (MAC), and general endotracheal anaesthesia (GETA) (see Table 1).

As noted by Groen et $\mathrm{al}^{24}$ "respondents could report having more than one surgical condition". Therefore, in the SOSAS paper they reported 'respondents in need of surgical care' rather than the absolute number of surgical conditions. To address this issue in our analysis, we selected the highest-level anaesthetic technique required for at least one of the respondents' surgical conditions.

Table 1 Anæsthetic requirement by surgical procedure / condition ordered by increasing complexity, costlier equipment and supplies, and higher training level of personnel.

\begin{tabular}{|c|c|c|}
\hline $\begin{array}{l}\text { Type of } \\
\text { anasthetic }\end{array}$ & Description & Criteria (Examples) \\
\hline $\begin{array}{l}\text { Minimal } \\
\text { anæesthesia }\end{array}$ & $\begin{array}{l}\text { Topical or sub-cutaneous } \\
\text { local anæsthetic infiltration } \\
\text { by non-anæsthesia personnel. }\end{array}$ & $\begin{array}{l}\square \text { All procedures for dental and ophthalmic } \\
\text { conditions not resulting from injury }\end{array}$ \\
\hline MAC & $\begin{array}{l}\text { Sedation with ketamine } \\
\text { and/or benzodiazepines. }\end{array}$ & $\begin{array}{l}\square \text { All procedures for non-disabling back, neck, } \\
\text { head, chest and breast conditions. } \\
\square \text { All non-injury related abdominal wounds, and } \\
\text { soft reducible masses. }\end{array}$ \\
\hline $\begin{array}{l}\text { Spinal } \\
\text { anæsthesia }\end{array}$ & $\begin{array}{l}\text { Local anæsthetic injected } \\
\text { into the intrathecal space } \\
\text { (may include sedation as in } \\
\text { MAC). }\end{array}$ & $\begin{array}{l}\square \text { All lower extremity and groin procedures } \\
\text { (including inguinal herniæ). } \\
\square \text { Procedures for obstructed labour or 'inability to } \\
\text { urinate'. }\end{array}$ \\
\hline GETA & $\begin{array}{l}\text { General anæsthesia with } \\
\text { endotracheal intubation, } \\
\text { maintained with inhaled } \\
\text { agents. }\end{array}$ & $\begin{array}{l}\square \text { All procedures for eye, head and neck injuries, } \\
\text { and ENT, upper extremity and abdominal } \\
\text { conditions not suitable for above anæsthetic } \\
\text { types. } \\
\square \text { All significantly disabling conditions. }\end{array}$ \\
\hline
\end{tabular}

\section{Findings}

Our analysis of the SOSAS dataset revealed that $92 \%$ (687 of 745) of untreated surgical conditions in Sierra Leone would require some form of anaesthesia. Seventeen per cent (125 of 745) would require MAC, $22 \%$ (167 of 745 ) would require spinal anaesthesia, and $53 \%$
(395 of 745) would require GETA (Table 2).

Using the extrapolated numbers from Groen et al, ${ }^{24}$ if 1.5 million Sierra Leoneans potentially need surgery today, then up to 795000 (53\%) will need a GETA, $330000(22 \%)$ will need spinal anaesthesia, and 255000 (17\%) will need MAC. 
Table 2 Distribution of anaesthetic types needed for untreated surgical conditions.

\begin{tabular}{|c|c|c|c|c|c|c|c|}
\hline Anatomic Site & $\begin{array}{l}\# \\
\text { Needing } \\
\text { surgery }\end{array}$ & \multicolumn{2}{|l|}{ Categories } & $\begin{array}{l}\text { Minimal } \\
\text { anasthesia }\end{array}$ & MAC & Spinal & GETA \\
\hline \multirow{2}{*}{ Eye } & \multirow{2}{*}{52} & \multicolumn{2}{|l|}{ Injury } & & & & 13 \\
\hline & & \multicolumn{2}{|l|}{ Non-injury } & 39 & & & \\
\hline ENT & \multicolumn{3}{|l|}{19} & & & & 19 \\
\hline \multirow{2}{*}{$\begin{array}{l}\text { Dental } \\
\text { mouth }\end{array}$} & \multirow{2}{*}{22} & \multicolumn{2}{|l|}{ Injury } & & & & 3 \\
\hline & & \multicolumn{2}{|l|}{ Non-injury } & 19 & & & \\
\hline \multirow{2}{*}{ Neck } & \multirow{2}{*}{27} & \multicolumn{2}{|c|}{ NO disability (0 injuries) } & & 9 & & \\
\hline & & \multicolumn{2}{|c|}{ Significant disability } & & & & 18 \\
\hline \multirow{3}{*}{ Head } & \multirow{3}{*}{36} & \multirow[b]{2}{*}{$\begin{array}{l}\mathrm{NO} \\
\text { disability }\end{array}$} & Injury & & & & 1 \\
\hline & & & $\begin{array}{l}\text { Non- } \\
\text { injury }\end{array}$ & & 17 & & \\
\hline & & \multicolumn{2}{|c|}{ Significant disability } & & & & 18 \\
\hline \multirow{2}{*}{ Chest / breast } & \multirow{2}{*}{60} & \multicolumn{2}{|c|}{ NO disability } & & 34 & & \\
\hline & & \multicolumn{2}{|c|}{ Significant disability } & & & & 26 \\
\hline \multirow{2}{*}{ Back } & \multirow{2}{*}{58} & \multicolumn{2}{|c|}{ NO disability } & & 19 & & \\
\hline & & \multicolumn{2}{|c|}{ Significant disability } & & & & 39 \\
\hline \multirow{9}{*}{ Abdominal } & \multirow{9}{*}{299} & Injury & & & & & 20 \\
\hline & & Wounds (n & injury) & & 6 & & \\
\hline & & Solid mass & & & & & 15 \\
\hline & & Soft, reduc & mass & & 40 & & \\
\hline & & $\begin{array}{l}\text { Deformity } \\
\text { (congenital }\end{array}$ & acquired) & & & & 5 \\
\hline & & Rectal blee & & & & & 18 \\
\hline & & $\begin{array}{l}\text { Abdominal } \\
\text { distension }\end{array}$ & pain / & & & & 165 \\
\hline & & Obstructed & our & & & 15 & \\
\hline & & Inability to & nate & & & 15 & \\
\hline & & Burn / inju & & & & 2 & \\
\hline & & Solid mass & testicular) & & & 7 & \\
\hline & & Inguinal he & & & & 34 & \\
\hline Groin & 69 & $\begin{array}{l}\text { Deformity } \\
\text { (congenital }\end{array}$ & acquired) & & & 15 & \\
\hline & & Fistula & & & & 2 & \\
\hline & & Hæmaturia & & & & & 9 \\
\hline Fvtromitios & 103 & Upper & & & & & 26 \\
\hline Extremitues & 103 & Lower & & & & 77 & \\
\hline Total & 745 & & & 258 & 125 & 167 & 395 \\
\hline & & & & $7 \cdot 79 \%$ & $16 \cdot 78 \%$ & $22 \cdot 42 \%$ & $53.02 \%$ \\
\hline
\end{tabular}

\section{Discussion}

Sierra Leone has a large unmet surgical need, most of which $(92 \%)$ would require some form of anaesthesia. The factors limiting provision of this anaesthesia care are myriad and common throughout LMICs. ${ }^{2-18}$ The re- cent Ebola epidemic, with the tragic loss of many vital providers has exacerbated these problems.

In some $\mathrm{LMICs}^{25}$ there are disproportionately fewer anaesthesia-providers than surgeons, making anaesthesia manpower the 'rate-limiting factor' in unmet surgi- 
cal need. Before the Ebola epidemic, Sierra Leone had 30 surgical providers and 32 anaesthesia providers for a country of six million. ${ }^{21}$ Now, sadly, there are many fewer. Most of these providers are located in the larger urban centres which have only $39 \%$ of the population. ${ }^{26}$ This leaves the district hospitals short-staffed, although proportionately so. There is little doubt that both surgical and anaesthesia manpower must be increased in parallel if the unmet surgical need is to be addressed.

As of 2009 there were three anaesthesia machines ${ }^{19}$ and few vital signs monitors ${ }^{21}$ scattered over nine general hospitals in Sierra Leone.Oxygen is mostly supplied by concentrators, which malfunction frequently.19 Municipal electricity and water supplies are unreliable. Surgical patients' families often must provide funds for fuel for the hospital's electricity generator during their relative's surgery. ${ }^{19,21}$

This analysis provides guidance as to rational and efficient training of personnel, and equipment purchase and distribution. Fifty-three per cent of unmet surgical need in Sierra Leone would require GETA, and a significant proportion $(39 \%)$ of procedures could be conducted with a spinal anaesthesia or MAC. This twotier construct reflects practicalities, and highlights the large gap between de facto practice and ideal systems of care. The World Federation of Societies of Anaesthesiologists $^{27}$ and the World Health Organization ${ }^{28}$ clearly delimit personnel able to provide different levels of anaesthesia care. It is considerably more expensive and time-consuming to train a physician than a nurse or anaesthesia officer, ${ }^{9}$ and these mid-level professionals could provide much of the unmet anaesthetic need with lower level anaesthetics. As numbers of credentialed providers are recovered, there may be an opportunity to judiciously recruit and train distinct personnel to provide different levels of anaesthetic services at appropriate surgical sites.

Medication and equipment acquisition could be prioritized to procedurally appropriate facilities. Although there are recognised minimum drug and equipment standards for any anesthetizing location, ${ }^{27,28}$ there is an opportunity to focus drugs and equipment required for higher level anaesthesia in those centres with the appropriate patients, and surgical and anaesthesia personnel. A successful surgical procedure requires a multiplicity of personnel and processes functioning in synchrony. To address surgical deficit one must encompass all of these variables. An analysis of this type, in which we examine the anesthetic counterpart of unmet surgical need, is a key part of planning for increasing surgical capacity.

\section{Limitations}

As noted by Groen et $\mathrm{al}^{24}$ this data relies on respondent self-reportage, both of the existence of a condition, and its amenability to surgical correction. In the SOSAS study this limitation is offset by the fact that the reported condition must still be assessed by a surgical healthcare professional to consider operative intervention. In our analysis we assume that surgical intervention would be carried out for conditions reported by the respondents. This could lead to an overestimation of surgical and therefore anaesthetic need.

Categorization of surgical procedures into specific anaesthesia types is based on subjective judgment and is inherently debatable. Our approach to categorization was to suggest techniques currently implemented by practitioners in Sierra Leone, and indeed most of West Africa. For ambiguous situations, we chose the simplest anaesthetic technique that would be safe and effective for the condition and procedure described. This rationale provides a practical template most likely to reflect clinical practice influenced by drug availability, personnel training and availability, and tolerability of specific surgical procedures. It assumes different standards of safety and monitoring than exists in other systems, ${ }^{5}$ and this may over-estimate the number of patients willing to undergo a surgical procedure. Cultural acceptance of surgical need or anaesthetic services may vary widely, and therefore the chosen anaesthetic technique for a particular procedure will ultimately be determined by patient preference.

The SOSAS tool has been validated for surgical disease burden, ${ }^{23}$ but not anaesthesia burden, and was not constructed with an anaesthesia analysis in mind. Many questions that would have eased prediction of anaesthesia type were omitted. Therefore, extrapolation from this data to infer anaesthesia techniques requires many 'leaps'. Moreover, we are extrapolating from Sierra Leonean practitioners' current standards, to predict care that they are not currently providing.

In many ways Sierra Leone is representative of LMICs, with limited access to healthcare, low life expectancy at 
birth, and a high maternal mortality. ${ }^{26}$ At number 183 , however, it currently ranks as one of the lowest of the 187 nations on the UN Development Index. ${ }^{29}$ Therefore, the ability to extrapolate Sierra Leone's anaesthesia need data to other LMICs is somewhat limited. However, the process of generating and analysing such data may prove very useful to other LMICs seeking to rationally build capacity and satisfy their own unmet surgical and anaesthesia need.

\section{Summary}

Specific assessment of anaesthesia needs is warranted in LMICs to address this important component of global health. Such assessments can ensure that the training and distribution of local personnel, and the acquisition and distribution of anaesthesia equipment and drugs are tailored to the specific anaesthesia needs of a community.

\section{Acknowledgments}

We would like to recognize the dedication and collaborative initiative of the SOSAS organization and their partners in Sierra Leone. The world's health problems are myriad, and without open and concerted engagement the venture will be that much harder.

\section{References}

1. How we Classify Countries | Data. dataworldbankorg. Available at: http://data.worldbank.org/about/country-classifications. Accessed July 31, 2013.

2. Hodges SC, Mijumbi C, Okello M, McCormick BA, Walker IA, Wilson IH. Anaesthesia services in developing countries: defining the problems. Anaesthesia. 2007;62(1):4-11. doi:10.1111/ j.1365-2044.2006.04907.x.

3. Cherian MN, Merry AF, Wilson IH. The World Health Organization and anaesthesia. Anaesthesia. 2007;62 Suppl 1:65-66. doi:10.1111/j.1365-2044.2007.05302.x.

4. Jochberger S, Ismailova F, Lederer W, et al. Anesthesia and its allied disciplines in the developing world: a nationwide survey of the Republic of Zambia. Anesth Analg. 2008;106(3):942-948. doi:10.1213/ane. 0b013e318166ecb8.

5. Walker IA, Wilson IH. Anaesthesia in developing countries--a risk for patients. Lancet. 2008;371(9617):968969. doi:10.1016/S0140-6736(08)60432-8.

6. Bösenberg AT. Pediatric anesthesia in developing countries. Curr Opin Anaesthesiol. 2007;20(3):204-210. doi:10.1097/ACO.0b013e3280c60c78.
7. Nambiar B, Lewycka S, Mwansambo C, Costello A. Planning health care in developing countries. $A n$ aesthesia. 2007;62 Suppl 1:5-10. doi:10.1111/j.13652044.2007.05290.x.

8. Linden AF, Sekidde FS, Galukande M, Knowlton LM, Chackungal S, McQueen KA. Challenges of surgery in developing countries: a survey of surgical and anesthesia capacity in Uganda's public hospitals. World J Surg. 2012;36(5):1056-1065. doi:10.1007/s00268-012$1482-7$.

9. Dubowitz G, Detlefs S, McQueen KA. Global anesthesia workforce crisis: a preliminary survey revealing shortages contributing to undesirable outcomes and unsafe practices. World J Surg. 2010;34(3):438-444. doi:10.1007/s00268-009-0229-6.

10. Notrica MR, Evans FM, Knowlton LM, McQueen KA. Rwandan surgical and anesthesia infrastructure: a survey of district hospitals. World J Surg. 2011;35(8):1770-1780. doi:10.1007/s00268-011-11254.

11. Penoyar T, Cohen H, Kibatala P, et al. Emergency and surgery services of primary hospitals in the United Republic of Tanzania. BMJ Open. 2012;2(1):e000369_ e000369. doi:10.1136/bmjopen-2011-000369.

12. Jochberger S, Bataar O, Mendsaikhan N, et al. Anesthesia care in a medium-developed country: a nationwide survey of Mongolia. J Clin Anes. 2010;22(6):443449. doi:10.1016/j.jclinane.2009.12.005.

13. Bainbridge D, Martin J, Arango M, Cheng D. Perioperative and anaesthetic-related mortality in developed and developing countries: a systematic review and meta-analysis. Lancet. 2012;380(9847):1075-1081. doi:10.1016/S0140-6736(12)60990-8.

14. Khan MU, Khan FA. Anaesthesia-related mortality in developing countries. Anaesthesia and intensive care. 2006;34(4):523-524.

15. Fisher QA, Nichols D, Stewart FC, Finley GA, Magee WP, Nelson K. Assessing pediatric anesthesia practices for volunteer medical services abroad. Anesthesiology. 2001;95(6):1315-1322.

16. Lagasse RS. Anesthesia safety: model or myth? A review of the published literature and analysis of current original data. Anesthesiology. 2002;97(6):1609-1617.

17. Glenshaw M, Madzimbamuto FD. Anaesthesia associated mortality in a district hospital in Zimbabwe: 1994 to 2001. Cent Afr J Med. 2005;51(3-4):39-44.

18. McKenzie AG. Mortality associated with anaesthesia at Zimbabwean teaching hospitals. S Afr Med J. 1996;86(4):338-342. 
19. KinghamTP, Kamara TB, Cherian MN, et al. Quantifying surgical capacity in Sierra Leone: a guide for improving surgical care. Arch Surg. 2009;144(2):122-7discussion 128. doi:10.1001/archsurg.2008.540.

20. Kushner AL, Cherian MN, Noel L, Spiegel DA, Groth S, Etienne C. Addressing the Millennium Development Goals from a surgical perspective: essential surgery and anesthesia in 8 low- and middle-income countries. Arch Surg. 2010;145(2):154-159. doi:10.1001/ archsurg.2009.263.

21. Groen RS, Kamara TB, Dixon-Cole R, Kwon S, Kingham TP, Kushner AL. A Tool and Index to Assess Surgical Capacity in Low Income Countries: An Initial Implementation in Sierra Leone. World J Surg. 2012. doi:10.1007/s00268-012-1591-3.

22. Humanitariansurgery.org. Available at: http://www. humanitariansurgery.org. Accessed May 28, 2013.

23. Groen RS, Samai M, Petroze RT, et al. Pilot Testing of a Population-based Surgical Survey Tool in Sierra Leone. World J Surg. 2012;36(4):771-774. doi:10.1007/ s00268-012-1448-9.

24. Groen RS, Samai M, Stewart K-A, et al. Untreated surgical conditions in Sierra Leone: a cluster randomised, cross-sectional, countrywide survey. Lancet. 2012;380(9847):1082-1087. doi:10.1016/S0140-
6736(12)61081-2.

25. Lebrun DG, Saavedra-Pozo I, Agreda-Flores F, Burdic ML, Notrica MR, McQueen KA. Surgical and anesthesia capacity in Bolivian public hospitals: results from a national hospital survey. World J Surg. 2012;36(11):2559-2566.doi:10.1007/s00268-0121722-x.

26. Sierra Leone statistics summary (2002 - present). Global Atlas of the Health Workforce, World Health Organization, Geneva. Available at: http://apps.who. int/gho/data/view.country.17800. Accessed June 16, 2013.

27. International Standards for a Safe Practice of Anaesthesia 2010 — WFSA. anaesthesiologistsorg. Available at: http://www.anaesthesiologists.org/guidelines/ practice/2008-international-standards-for-a-safe-practice-of-anaesthesia. Accessed June 12, 2013.

28. World Health Organization. WHO Guidelines for Safe Surgery 2009. 2009;5. Available at: http://www who int/patientsafety/safesurgery/knowledge_base/ SSSL_Brochure_finalJun08 pdf.

29. International Human Development Indicators - UNDP. hdrstatsundporg. Available at: http://hdrstats. undp.org/en/countries/profiles/SLE.html. Accessed June 16, 2013. 